\title{
Bone Selective Protective Effect of a Novel Bone-seeking Estrogen on Trabecular Bone in Ovariectomized Rats
}

\author{
Qiang Zhao $\cdot$ Xiaodong Liu $\cdot$ Lianfang Zhang $\cdot$ \\ Xing Shen · Jin Qi · Jinshen Wang • \\ Niandong Qian · Lianfu Deng
}

Received: 4 November 2012/Accepted: 19 April 2013/Published online: 19 June 2013

(C) The Author(s) 2013. This article is published with open access at Springerlink.com

\begin{abstract}
The drawbacks of estrogen restrict the clinical use of hormone replacement therapy, and it would be most helpful to explore new estrogenic substances that could prevent bone loss and be free from any adverse effects. We synthesized a new compound named bone-seeking estrogen $\left(\mathrm{SE}_{2}\right)$ by combining $17 \beta$-estradiol $\left(\mathrm{E}_{2}\right)$ with iminodiacetic acid through the Mannich reaction. $\mathrm{E}_{2}$ and $\mathrm{SE}_{2}$ were labeled with isotope ${ }^{3} \mathrm{H}$, and the tissue distribution tests of $\mathrm{E}_{2}-{ }^{3} \mathrm{H}$ and $\mathrm{SE}_{2}-{ }^{3} \mathrm{H}$ were analyzed by the radioactivity. The specific nuclear binding of $\mathrm{E}_{2}$ and $\mathrm{SE}_{2}$ in osteoblasts was measured. $\mathrm{SE}_{2}$ exhibited significantly greater affinity for bone but lower affinity for ovary and uterus than did $\mathrm{E}_{2}$, and $\mathrm{SE}_{2}$ maintained a high affinity for the estrogen receptor alpha similar to that of $\mathrm{E}_{2} . \mathrm{SE}_{2}$ administration did not induce uterine hypertrophy. Body weight increase was significantly suppressed by treatment with $\mathrm{E}_{2}$ but not by $\mathrm{SE}_{2}$ after ovariectomy (OVX). $\mathrm{SE}_{2}$ decreased bone turnover as $E_{2}$ after OVX detected by serum biochemical markers. Bone histology and micro-CT analysis revealed that $\mathrm{SE}_{2}$ administration, similar to $\mathrm{E}_{2}$, could improve bone
\end{abstract}

The first two authors contributed equally to this article, and both should be considered first author.

The authors report that they have no conflict of interest.

Q. Zhao $\cdot$ L. Zhang $\cdot$ X. Shen $\cdot$ J. Qi $\cdot$ J. Wang $\cdot$ N. Qian ·

L. Deng ( ( )

Shanghai Key Laboratory for Bone and Joint Disease, Shanghai Institute of Traumatology and Orthopaedics, Ruijin Hospital, Shanghai Jiao Tong University School of Medicine, 197 Ruijin 2nd Road, Shanghai 200025, People's Republic of China e-mail: 1fdeng@msn.com

\section{Liu}

Orthopaedics Department, Central Hospital of the YangPu

District, 450 Tengyue Road, Shanghai 200090,

People's Republic of China mass and trabecular architecture after OVX. Biomechanical analyses showed that $\mathrm{SE}_{2}$ treatment effectively increased mechanical properties after OVX. The results suggested that $\mathrm{SE}_{2}$ was effective in preventing OVXinduced bone loss and exhibited few side effects on body weight and uterine hypertrophy, which was beneficial in reducing the adverse effects caused by $\mathrm{E}_{2} . \mathrm{SE}_{2}$ may be a better choice than $E_{2}$ for the prevention of postmenopausal osteoporosis.

Keywords Bone-seeking estrogen - Estrogen · Postmenopausal osteoporosis - Side effects - Trabecular architecture

\section{Introduction}

The prevalence of osteoporosis is increasing and causing a substantial health burden. Osteoporosis is a skeletal disease characterized by low bone mass and microarchitectural deterioration with a resulting increase in bone fragility and subsequent susceptibility to fracture [1]. Estrogen deficiency after menopause is one of the most common causes of osteoporosis. The osteoblasts and osteoclasts have estrogen receptors, and estrogen affects bones partly by these receptors. It has been proposed that estrogen causes depletion in the number of osteoclasts in bone by inhibiting maturation at the cellular level while enhancing the synthesis of cytokines that play roles in bone formation [2,3]. In the estrogen-deficient state, such as in menopause, the balance between bone resorption and bone formation shifts toward an increasing level of bone resorption, with more resorption than formation; this results in the loss of bone mass and deterioration of trabecular bone microarchitecture. The estrogen-dependent increase in bone resorption 
and loss of bone mass are greatly accelerated in the first 5-10 years after menopause $[4,5]$.

The antiresorptive agents such as calcitonin and bisphosphonates and agents that stimulate bone formation such as sodium fluoride, as well as selective estrogen receptor modulators (SERMs) are commonly used for postmenopausal osteoporosis drug therapies. Because these drugs have been reported to exert undesirable side effects and do not produce bone mass of a desirable quality, there is a clear need for the development the novel agents that exhibit a low level of toxicity and side effects as new treatment options for osteoporosis [6-9]. Hormone replacement therapy (HRT) is also used commonly to prevent bone loss. However, there is evidence that the use of estrogen increases the risk of uterine bleeding and hyperplasia, endometrial, breast and ovarian cancer, venous thromboembolism [10-14], thrombotic stroke, myocardial infarction and cardiovascular disease [15, 16]. These potential drawbacks restrict the clinical use of HRT, and it would be most helpful to explore new estrogenic substances that could prevent bone loss and be free from any adverse effects.

Iminodiacetic acid [IDA, $\mathrm{NH}\left(\mathrm{CH}_{2} \mathrm{COOH}\right)_{2}$, structure formula as in Fig. 1a] is a calcium chelator that has a high affinity for calcium in the clinical treatment of heavy metal poisoning, and inactivation of iminodiacetate resin-induced factors VIII and V is because of direct deprivation of metal ions, predominantly $\mathrm{Ca}^{2+}$ [17]. It is well known that bone contains abundant calcium, and it is reasonable to assume that IDA could concentrate in bone by combining with calcium. Several approaches for conjugating a bone-seeking agent, including a bisphosphonate or a tetracycline with bone-preserving agents such as estrogens and prostaglandin $\mathrm{E}_{1}$, had been reported [18, 19]. However, estrogen bisphosphonate conjugates with low or high cleavage rate, as well as 17-estradiol, provided similar bone and uterus protection when compared on a molar basis, suggesting similar systemic levels of 17-estradiol. The theoretical approach of targeting 17-estradiol at bone by a potential bone-seeking pro-drug inducing no or only negligible systemic efficacy could not be realized $[20,21]$. The estrogen that was modified by tetracycline declined in biological activity [22], and the complex chemical structure and poor stability of tetracycline during chemical conjugation limit the feasibility of using tetracycline as an osteotropic agent [18].

A novel tetracycline-derived bone-targeting agent containing elements of the tricarbonylmethane system of ring A of tetracycline was developed to improve the safety profile that reduce nonbone effects such as cancer, uterine hypertrophy and clotting-related troubles of estradiol in the treatment of osteoporosis [23]. By combining 17 $\beta$-estradiol with IDA through the Mannich reaction in the presence of $37 \%$ formaldehyde, a new compound was synthesized that we named bone-seeking estrogen $\left(\mathrm{SE}_{2}\right)$ (patent $\mathrm{CN}$ 1211395C) (Fig. 1b). We hypothesized that the $\mathrm{SE}_{2}$ could also concentrate in bone using IDA as a guide. The aim of our present study was to investigate the tissue distribution, activity and effects of $\mathrm{SE}_{2}$ on the bone mineral density (BMD) and microarchitecture of trabecular bone in ovariectomized (OVX) rats.

\section{Methods}

Distribution of IDA in the Organs of Mice

Six-week-old female C57/BL mice were purchased by the Chinese Academy of Sciences, China. IDA were labeled with isotope ${ }^{3} \mathrm{H}$, and IDA- ${ }^{3} \mathrm{H}$ was administered through intramuscular or intravenous injection. The mice were killed, and bone, kidney, spleen, lung, liver, blood and muscle were collected after 1 and $24 \mathrm{~h}$ to analyze the distribution of IDA in the organs. Disintegrations per minute (DPM) of ${ }^{3} \mathrm{H}$ intake was measured by liquid scintillation spectrometry to analyze indirectly the concentration of IDA in the tissue. All procedures involving animals were approved by the Shanghai Jiaotong University Animal Study Committee and were carried out in accordance with the guide for the humane use and care of laboratory animals.

\section{Tissue Distribution Test of $\mathrm{SE}_{2}$}

Mice were divided randomly into $\mathrm{E}_{2}$ and $\mathrm{SE}_{2}$ groups. $\mathrm{E}_{2}$ and $\mathrm{SE}_{2}$ were labeled with isotope ${ }^{3} \mathrm{H}$, and $\mathrm{E}_{2}{ }^{3} \mathrm{H}$ and $\mathrm{SE}_{2}{ }^{3} \mathrm{H}$ were diluted to the concentration of $30 \mu \mathrm{Ci} / \mathrm{ml}$. The animals were injected through the caudal vein at a dose of $0.005 \mathrm{ml} / \mathrm{g}$. After 1, 2, 4, 8, 12, $24 \mathrm{~h}, 3,5,7,10$ and 14 days, six mice from each group were killed. Uterus, ovary and bone including skull, femur, second lumbar vertebra were collected. DPM of ${ }^{3} \mathrm{H}$ intake was measured by liquid scintillation spectrometry to analyze indirectly concentration of $\mathrm{E}_{2}$ and $\mathrm{SE}_{2}$ in the tissue, respectively.

\section{Activity Test of $\mathrm{SE}_{2}$}

Compared with $\mathrm{E}_{2}$, the properties of $\mathrm{SE}_{2}$ might be changed since $\mathrm{E}_{2}$ was modified with IDA. Receptor affinity test was used to verify whether $\mathrm{SE}_{2}$ remained the same as the biological activity of the $E_{2}$ binding its receptor. Calvaria of newborn mice were sequentially digested twice with $0.25 \%$ trypsin at $37{ }^{\circ} \mathrm{C}$ for $20 \mathrm{~min}$, and the released osteoblasts were seeded in a culture dish in $3 \mathrm{ml}$ of Dulbecco modified Eagle medium containing $10 \%$ bovine serum, $100 \mathrm{U} / \mathrm{ml}$ penicillin and $100 \mu \mathrm{g} / \mathrm{ml}$ streptomycin. The medium was changed every 3 days. After reaching confluence, the cells were digested with $0.25 \%$ trypsin and subcultured at a 1:3 
Fig. 1 Molecular formula for IDA and the synthesis of $\mathrm{SE}_{2}$. The molecular formula for IDA (a) and $\mathrm{SE}_{2}$ was synthesized by combining $17 \beta$-estradiol with IDA through the Mannich reaction in the presence of $37 \%$ formaldehyde (b)
A

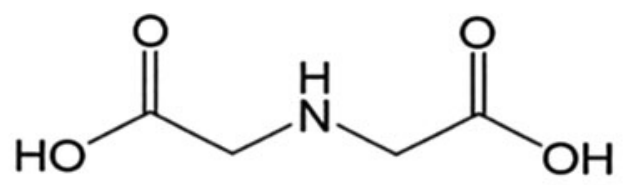

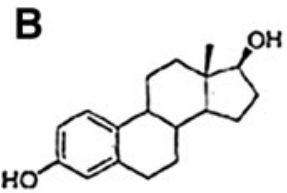

$\mathrm{E}_{2}$

37\%formaldehyde

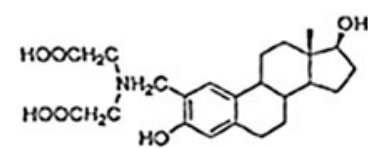

$\mathrm{SE}_{2}$ ratio. The second-generation osteoblasts were used in the nuclear binding assay. The specific nuclear binding of $E_{2}$ and $\mathrm{SE}_{2}$ in these cells was measured by a nuclear binding assay. In brief, osteoblasts were washed twice with phosphatebuffered saline and resuspended in homogenization buffer, then Dounce homogenized. The homogenate was centrifuged at $3,000 \times g$ for $10 \mathrm{~min}$ at $4{ }^{\circ} \mathrm{C}$ to yield a crude nuclear pellet. The nuclear pellet was resuspended in $10 \mathrm{mM}$ Tris$\mathrm{HCl}, 0.6 \mathrm{M} \mathrm{KCl}$ and Dounce homogenized at $4{ }^{\circ} \mathrm{C}$. An aliquot of the homogenate was saved for the DNA assay. The suspension was centrifuged at $105,000 \times g$ for $30 \mathrm{~min}$ at $4{ }^{\circ} \mathrm{C}$. Triplicate aliquots of the nuclear extract were incubated in $10 \mathrm{mM}$ Tris- $\mathrm{HCl}$ (pH 7.5), 2 mM EDTA, $0.5 \mathrm{mM}$ EGTA and $5 \mathrm{mM}$ dithiothreitol overnight at $4{ }^{\circ} \mathrm{C}$ with increasing concentrations $(0.065-10 \mathrm{nM})$ of $\mathrm{E}_{2}{ }^{3}{ }^{3} \mathrm{H}$ and $\mathrm{SE}_{2}{ }^{3} \mathrm{H}(37 \mathrm{MBq} / \mathrm{ml})$ in the absence or presence of a 200 -fold molar excess of unlabeled $\mathrm{E}_{2}$ or $\mathrm{SE}_{2}$. Free and receptor-bound $\mathrm{E}_{2}{ }^{-} \mathrm{H}$ and $\mathrm{SE}_{2}-{ }^{3} \mathrm{H}$ were separated using glucan-activated carbon suspensions. Binding data were analyzed by Scatchard analysis.

\section{Rats and Treatments}

Twelve-week-old female Sprague Dawley rats weighing 250-300 g were divided randomly into four groups. Group A animals were bilaterally ovariectomized and supplemented with vehicle (OVX, $n=24)$; group $\mathrm{B}$, bilaterally ovariectomized and supplemented with $\mathrm{SE}_{2}\left(\mathrm{SE}_{2}, n=24\right)$; group $\mathrm{C}$, bilaterally ovariectomized and supplemented with $17 \beta$ estradiol ( $\left.\mathrm{E}_{2}, n=24\right)$; and group $\mathrm{D}$, sham-operated control $(n=24)$. Rats were subcutaneously injected with vehicle in the sham-treated and OVX groups, or with $17 \beta$-estradiol $(10 \mu \mathrm{g} / \mathrm{kg} /$ day, which is the dose proven to be effective to prevent osteopenia in OVX rats [24]; Sigma Aldrich, USA), or $\mathrm{SE}_{2}$ (purity $99 \%, 15.32 \mu \mathrm{g} / \mathrm{kg} / \mathrm{day}$, an identical molar dose to $E_{2}$, synthesized by Shanghai Institute Material Medica, Chinese Academy of Sciences) in the $E_{2}$ and $\mathrm{SE}_{2}$ groups, respectively. The animals received an injection daily. $E_{2}$ and $\mathrm{SE}_{2}$ were dissolved in a small volume of absolute ethanol, and the concentration was adjusted with sesame oil [25]. All injections were administered subcutaneously in a volume of $0.2 \mathrm{~cm}^{3}$. The rats were given free access to distilled water.

After 12 weeks of treatment, the rats were humanely killed by overdose with pentobarbital sodium. Uteri of the rats were excised and weighed to evaluate the effects of OVX, and the femur and tibia were collected.

Body and Uterine Weight

Rats were weighed every week and their body weights recorded. At the end of the study, the uteri were collected and weighed. Then the uteri were fixed in $4 \%$ formaldehyde in $0.1 \mathrm{M}$ phosphate buffer, $\mathrm{pH} \mathrm{7.2,} \mathrm{for} 48 \mathrm{~h}$. Tissue specimens were embedded in paraffin, and 5 - $\mu \mathrm{m}$-thick sections, vertical to the long axis of the uterus, were cut and stained with hematoxylin and eosin.

\section{Serum Biochemical Markers of Bone Metabolism}

Serum osteocalcin levels and alkaline phosphatase (ALP) activities (both sensitive biochemical markers of bone formation) were determined using osteocalcin EIA kits (Nordic Bioscience Diagnostics, Herlev, Denmark) and QuantiChrome ALP assay kits (DALP-250, BioAssay Systems, CA, USA), respectively. Serum levels of C-terminal telopeptide fragment of type I collagen C-terminus (CTX), which is generated by the osteoclast and is a marker of bone resorption, were determined using RatLaps ELISA kits (Nordic Bioscience Diagnostics, Herlev, Denmark) [26].

\section{Bone Histology and Histomorphometric Analysis}

For decalcified sections, the right tibiae were dissected and fixed in $4 \%$ paraformaldehyde at $4{ }^{\circ} \mathrm{C}$ for $48 \mathrm{~h}$, then were decalcified in $10 \%$ EDTA for about 4 weeks. Afterward, bones were dehydrated in increasing concentrations of ethanol, cleared in xylene and embedded in paraffin. Serial $5-\mu \mathrm{m}$ sagittal sections of the tibiae were cut with a Leica microtome (Leica RM 2135, Germany) and placed on 
slides for hematoxylin and eosin staining. The sections were microphotographed (Leica, Germany) to allow histomorphometric measurements on the central area of the cancellous bone displayed on the digital image. Quantitative histomorphometric analysis was conducted in a blinded fashion with Leica Qwin Software. Bone volume per total volume (BV/TV, \%) and trabecular separation (Tb.Sp, $\mu \mathrm{m})$ in four randomly selected visual fields were detected, and six specimens in each group were examined.

\section{Microcomputed Tomography}

Bone histomorphometric parameters and the microarchitectural properties of the distal femurs were determined using a micro-CT system (Locus SP, GE Healthcare) with $\mathrm{X}$-ray energy settings of $55 \mathrm{kV}$ and $145 \mu \mathrm{A}$. Samples were scanned over one entire 3,600 rotation at an exposure time of $3,000 \mathrm{~ms} /$ frame. An isotopic resolution of $15-40 \mu \mathrm{m}$ voxel size that displayed the microstructure of the distal
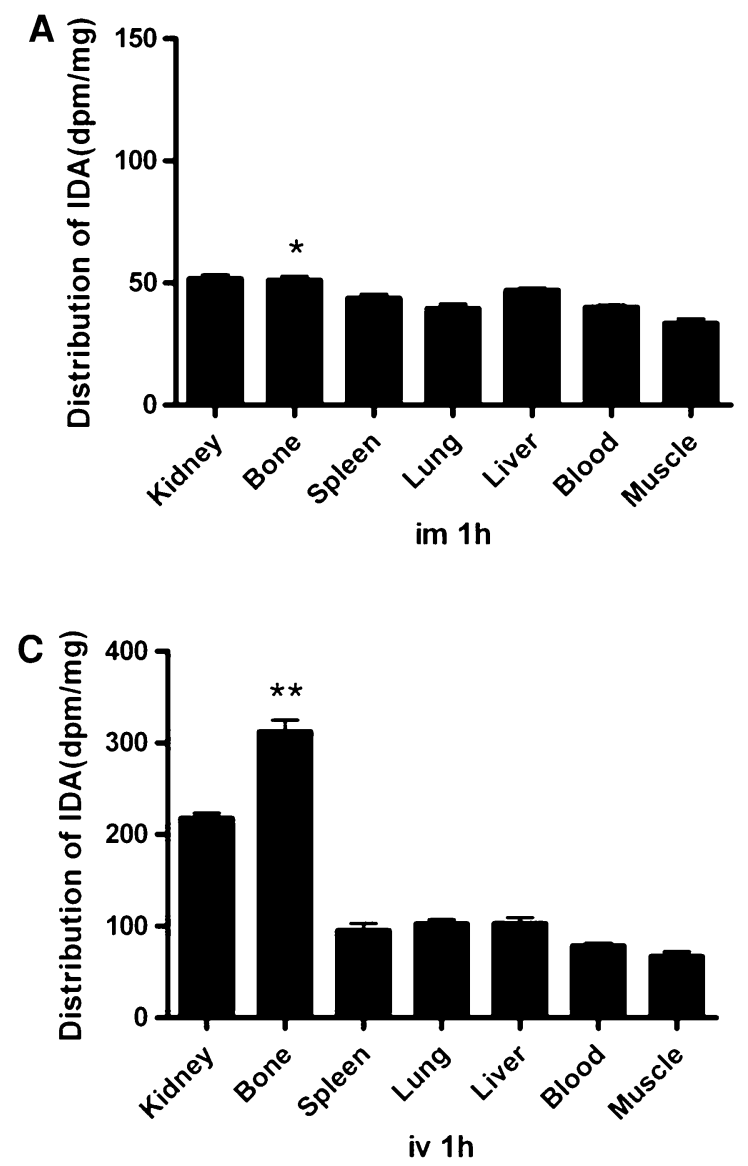

Fig. 2 Distribution of IDA in the organs of mice. IDA were labeled with isotope ${ }^{3} \mathrm{H}$, and IDA- ${ }^{3} \mathrm{H}$ was administered through intramuscular (im) $(\mathbf{a}, \mathbf{b})$ or intravenous (iv) (c, d) injection; mice were killed, and bone, kidney, spleen, lung, liver, blood and muscle were collected after 1 and 24 h to analyze the distribution of IDA in the organs. DPM of ${ }^{3} \mathrm{H}$ intake was measured with liquid scintillation spectrometry to analyze femurs was selected, and the angle of increment around the sample was set to 0.4 degrees, which resulted in the acquisition of 900 2D images. A modified Feldkamp conebeam algorithm was used for $3 \mathrm{D}$ reconstruction. For bone analysis, 2.5-mm-thick regions of the femur proximal to the growth plate of the knee joint were selected as the region of interest. Image information was obtained on the basis of the automatic domain values produced by the computer. The data were analyzed with Microview2.2 software. Threedimensional analyses were carried out, and for each sample BMD as well as trabecular structural parameters such as $\mathrm{BV} / \mathrm{TV}$, trabecular thickness (Tb.Th), trabecular number (Tb.N) and Tb.Sp were measured [27, 28].

Biomechanical Analyses

The femurs from all groups were flash frozen in liquid nitrogen immediately after the rats were killed and stored at $-80{ }^{\circ} \mathrm{C}$ for further mechanical testing. The femurs were
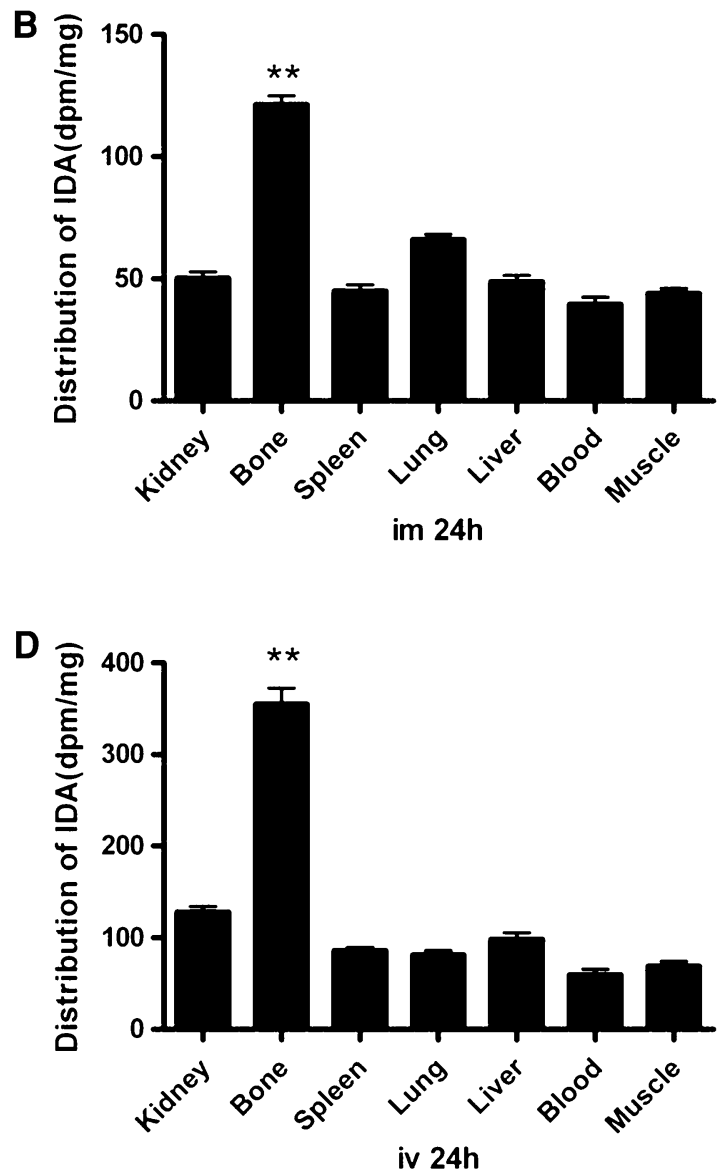

indirectly concentration of IDA in the tissue. The distribution of IDA in bone was significantly higher than spleen, lung, blood and muscle $(* p<0.05)$ and was no significant difference compare with kidney and liver after im $1 \mathrm{~h}(\mathbf{a})$. It was significantly higher than kidney, spleen, lung, blood, liver and muscle $(* * p<0.01)$ after im $24 \mathrm{~h}(\mathbf{b})$, iv $1 \mathrm{~h}$ (c) or iv $24 \mathrm{~h}$ (d). There were six replicate samples in each group 
thawed at room temperature before testing, and three-point bending of the right femora was carried out by an Instron 5569 materials testing machine (Instron Inc., MA). The femur was placed posterior side down between two supports $6 \mathrm{~mm}$ apart, and load was applied at the midspan, which made bending occur about the anteroposterior axis. Load-displacement curves were recorded at a crosshead speed of $1 \mathrm{~mm} / \mathrm{s}$ [29].

\section{Statistical Analysis}

Results are expressed as mean \pm standard deviation (SD). SPSS 13.0 software (Chicago, IL, USA) was used for the statistical analysis. The differences between the groups were compared using ANOVA with a Bonferroni's multiple-group comparison procedure. A $p$ value of $<0.05$ was accepted as statistically significant.

\section{Results}

IDA Showed High Affinity for Bone after Intramuscular or Intravenous Injection

The distribution of IDA in bone was significantly higher than spleen, lung, blood and muscle, and was no significant difference compared with kidney and liver after intramuscular (im) $1 \mathrm{~h}$ (Fig. 2a). It was significantly higher than kidney, spleen, lung, blood, liver and muscle after im $24 \mathrm{~h}$ (Fig. 2b), iv 1 h (Fig. 2c), or iv 24 h (Fig. 2d).

Tissue Distribution Test of $\mathrm{E}_{2}$ and $\mathrm{SE}_{2}$

After injection via the caudal vein, the DPM of $\mathrm{SE}_{2}-{ }^{3} \mathrm{H}$ in skull, femur and vertebrae were higher than $\mathrm{E}_{2}{ }^{3} \mathrm{H}$ from $2 \mathrm{~h}$ to 14 days. In contrast, the DPM of $\mathrm{SE}_{2}-{ }^{3} \mathrm{H}$ in mice ovary and uterus were significantly lower than $\mathrm{E}_{2^{-}}{ }^{3} \mathrm{H}$ from $2 \mathrm{~h}$ to 14 days (Fig. 3). These results showed that $E_{2}$ and $\mathrm{SE}_{2}$ were effectively conjugated with isotope ${ }^{3} \mathrm{H}$ and that $\mathrm{SE}_{2}$ had significant affinity for bone but lower affinity for ovary and uterus than did $\mathrm{E}_{2}$.

Nuclear Binding Assay of $\mathrm{E}_{2}$ and $\mathrm{SE}_{2}$

Saturability was shown for both $\mathrm{E}_{2}$ - and $\mathrm{SE}_{2}$-bound estrogen receptor alpha in osteoblasts, which coincided with ligand and receptor binding characteristics (Fig. 4a). Measured by Scatchard analysis, the affinities of $\mathrm{E}_{2}$ and $\mathrm{SE}_{2}$ for osteoblast estrogen receptors were $2.58 \times 10^{-10}$ and $2.82 \times$ $10^{-10} \mathrm{~mol} / \mathrm{L}$, respectively; therefore, the affinity of $\mathrm{SE}_{2}$ for osteoblast estrogen receptors was $92 \%$ that of $\mathrm{E}_{2}$ (Fig. $4 \mathrm{~b}$ ).
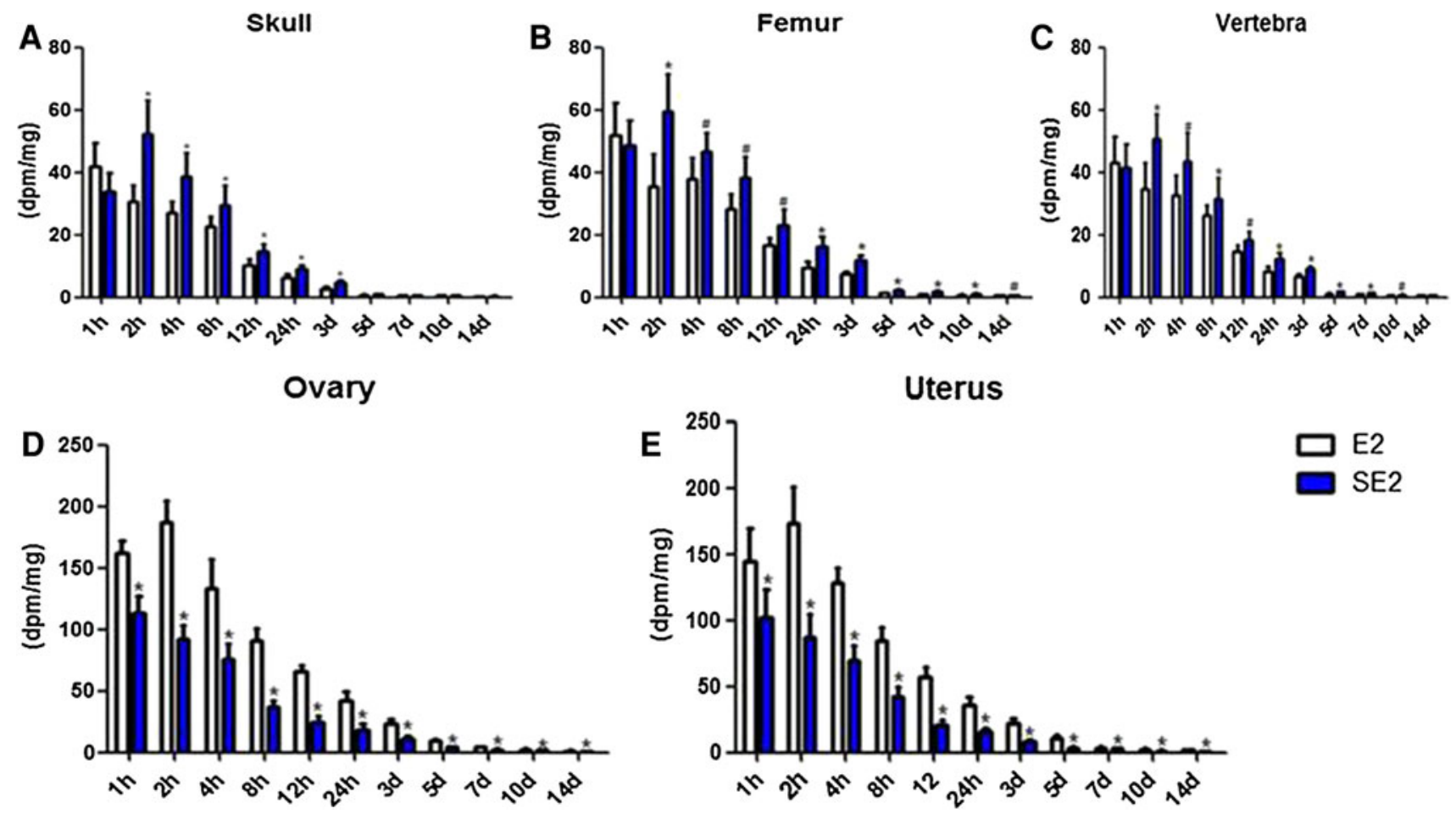

Fig. 3 Tissue distribution tests of $E_{2}$ and $S_{2} . E_{2}$ and $S_{2}$ were labeled with isotope ${ }^{3} \mathrm{H}$, and $\mathrm{E}_{2}{ }^{3} \mathrm{H}$ and $\mathrm{SE}_{2}{ }^{3} \mathrm{H}$ were injected through the caudal vein. Mice were killed, and skull, femur, second lumbar vertebra, uterus and ovary were collected to analyze the radioactivity. DPM of ${ }^{3} \mathrm{H}$ intake measured by liquid scintillation spectrometry to analyze indirectly concentration of $\mathrm{E}_{2}$ and $\mathrm{SE}_{2}$ in the tissue concentrations of $\mathrm{SE}_{2}$ in mice skull (a), femur (b) and vertebrae (c) were higher, respectively, than $\mathrm{E}_{2}$; concentrations of $\mathrm{SE}_{2}$ in mice ovary $(\mathbf{d})$ and uterus $(\mathbf{e})$ were significantly lower than $\mathrm{E}_{2}(* p<0.05$ compared with $\mathrm{E}_{2}$ ). There were six replicate samples in each group 

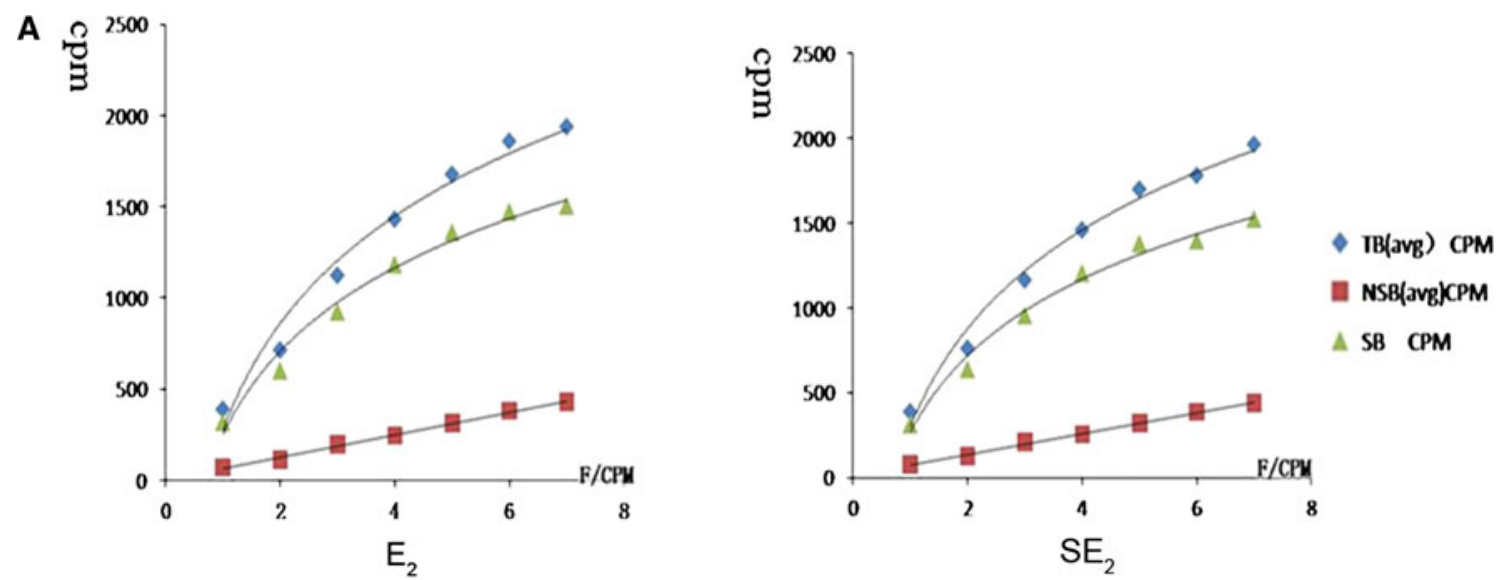

B

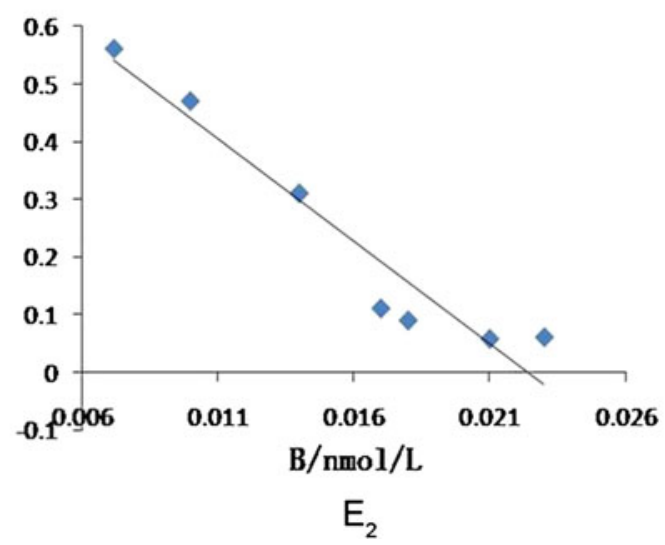

Fig. 4 Nuclear binding assay of $E_{2}$ and $\mathrm{SE}_{2}$. The specific nuclear binding of $\mathrm{E}_{2}$ and $\mathrm{SE}_{2}$ in osteoblasts was measured by a nuclear binding assay, and binding data were analyzed by Scatchard analysis. Saturability

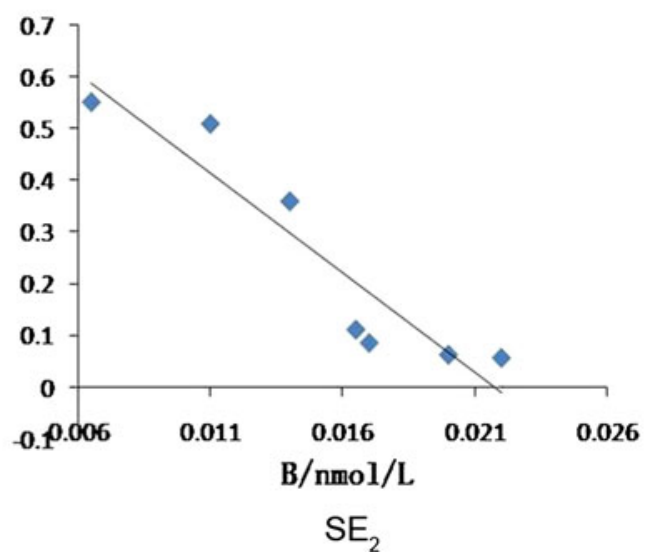

is shown for both $\mathrm{E}_{2}$ - and $\mathrm{SE}_{2}$-bound estrogen receptors in osteoblasts (a). The affinities of $\mathrm{E}_{2}$ and $\mathrm{SE}_{2}$ for estrogen receptors in osteoblasts were $2.58 \times 10^{-10}$ and $2.82 \times 10^{-10} \mathrm{~mol} / \mathrm{L}$, respectively $(\mathbf{b})$

\section{Uterine Histology and Body Weight}

After 12 weeks, the uteri of rats in the OVX group atrophied as evaluated by general uterine morphology, while $\mathrm{E}_{2}$ administration prevented the uterine atrophy similar to the sham-treated group; but $\mathrm{SE}_{2}$ administration had not prevent the uterine atrophy (Fig. 5a). Histomorphometric analysis further confirmed that endometria were atrophied in the OVX group and $\mathrm{E}_{2}$ prevented the uterine atrophy, but $\mathrm{SE}_{2}$ could not prevent it (Fig. 5b). As to uterine weights, the $\mathrm{SE}_{2}$ group was similar to the OVX group, and these weights were significantly lower than the $\mathrm{E}_{2}$ - and sham-treated groups (Fig. 5c). Results revealed that $\mathrm{E}_{2}$ could induce uterine hypertrophy after $\mathrm{OVX}$, but that $\mathrm{SE}_{2}$ did not show this side effect.

After 12 weeks, the body weights in $\mathrm{SE}_{2}$ group were similar to the OVX groups, but in the $\mathrm{E}_{2}$ - and sham-treated groups, the body weights were significantly lower than in the $\mathrm{SE}_{2}$ group (Fig. 5d).

\section{Serum Biochemical Markers of Bone Metabolism}

We found that the serum level of osteocalcin in the $\mathrm{SE}_{2}$ group was significantly lower than the OVX group and higher than the sham-treated group, and there was no significant difference compared with $\mathrm{E}_{2}$ group (Fig. 6a). As to another marker of bone formation, ALP, as well as the sensitive markers of bone resorption, CTX, results showed the serum levels of ALP and CTX in the $\mathrm{SE}_{2}$ group were also significantly lower than in the OVX group, and there was no significant difference compared with $\mathrm{E}_{2}$ - and shamtreated groups (Fig. 6b, c).

\section{Bone Histology and Histomorphometric Analysis}

The intertrabecular space at the proximal tibia of shamoperated rats was filled with trabecular bone, erythropoietic marrow and fat cells. OVX led to more fat cells and reduced amount of trabecular bone and erythropoietic 


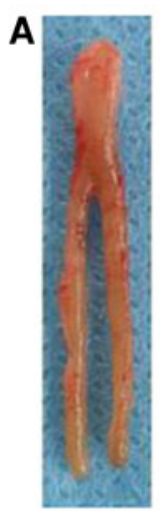

ovX

B

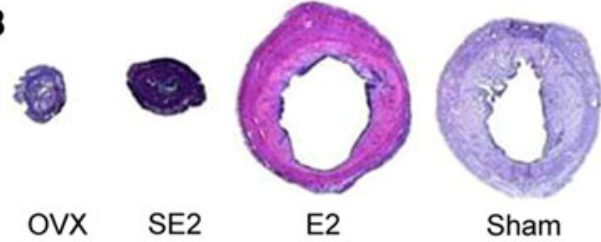

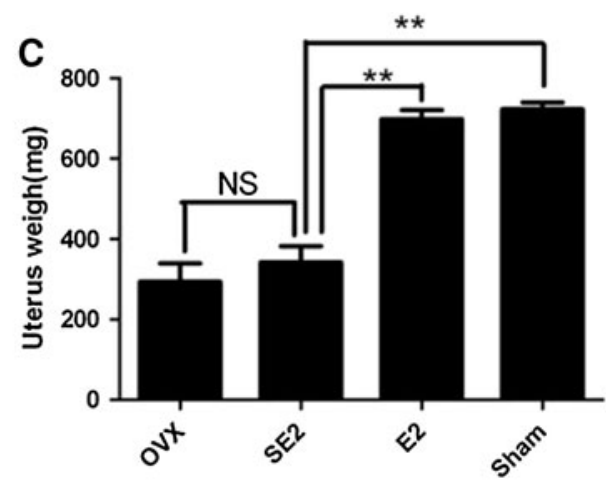

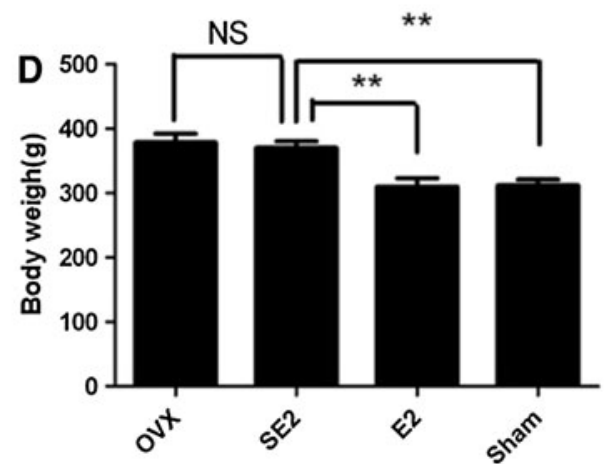

to those in the OVX group (NS, $p>0.05$ ) and were significantly lower than the $\mathrm{E}_{2}$ and sham-operated groups $(* * p<0.01)(\mathbf{c})$. The body weights in the $\mathrm{SE}_{2}$ group were similar to those in the OVX groups (NS, $p>0.05)$, but in the $\mathrm{E}_{2^{-}}$and sham-treated groups, the body weights were significantly lower than in the $\mathrm{SE}_{2}$ group $(* * p<0.01)(\mathbf{d})$. There were six replicate samples in each group
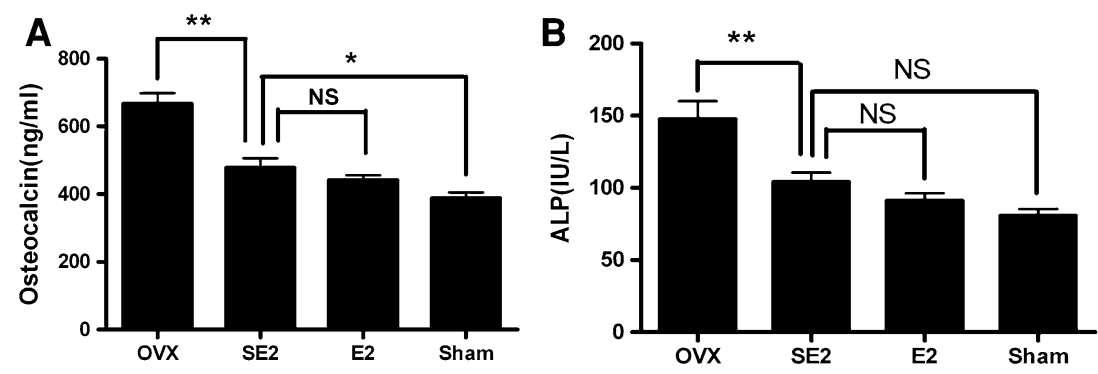

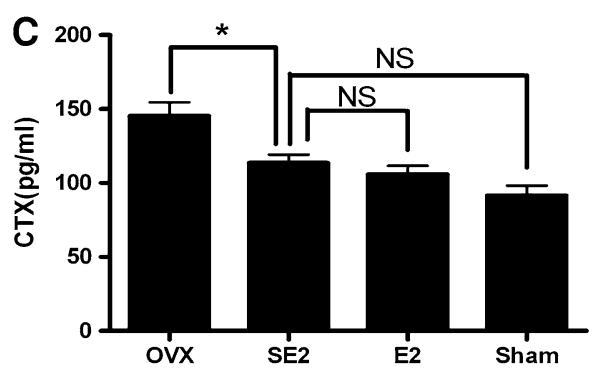

Fig. 6 Serum biochemical markers of bone metabolism. The serum level of osteocalcin in the $\mathrm{SE}_{2}$ group was significantly lower than in the OVX group $(* * p<0.01)$ and higher than the sham-treated group $\left({ }^{*} p<0.05\right)$; there was no significant difference compared with $\mathrm{E}_{2}$ group (NS, $p>0.05$ ) (a). The serum levels of ALP and CTX in the
$\mathrm{SE}_{2}$ group were significantly lower than in the OVX group $(* * p<0.01)$, and there was no significant difference compared with the $\mathrm{E}_{2}$ - and sham-treated groups (NS, $\left.p>0.05\right)(\mathbf{b}, \mathbf{c})$. There were six replicate samples in each group marrow. $\mathrm{SE}_{2}$ treatment was effective in maintaining the normal morphology at the proximal tibia compared to the OVX groups and was similar to the $\mathrm{E}_{2}$ group (Fig. 7a). Histomorphometric analysis further confirmed that the BV/ $\mathrm{TV}$ and $\mathrm{Tb} . \mathrm{Sp}$ in the $\mathrm{SE}_{2}$ group were significantly different compared with the OVX group, and similar to the $\mathrm{E}_{2^{-}}$and sham-treated groups (Fig. 7b, c).

\section{Micro-CT Analysis}

The bone mass and architecture in the OVX group were deteriorated after 12 weeks compared with the sham-treated group, and the indices in the $\mathrm{SE}_{2}$ group were better than those in the OVX group and similar to those of the $E_{2-}$ and sham-treated groups (Fig. 8a, b). BMD in the $\mathrm{SE}_{2}$ group 

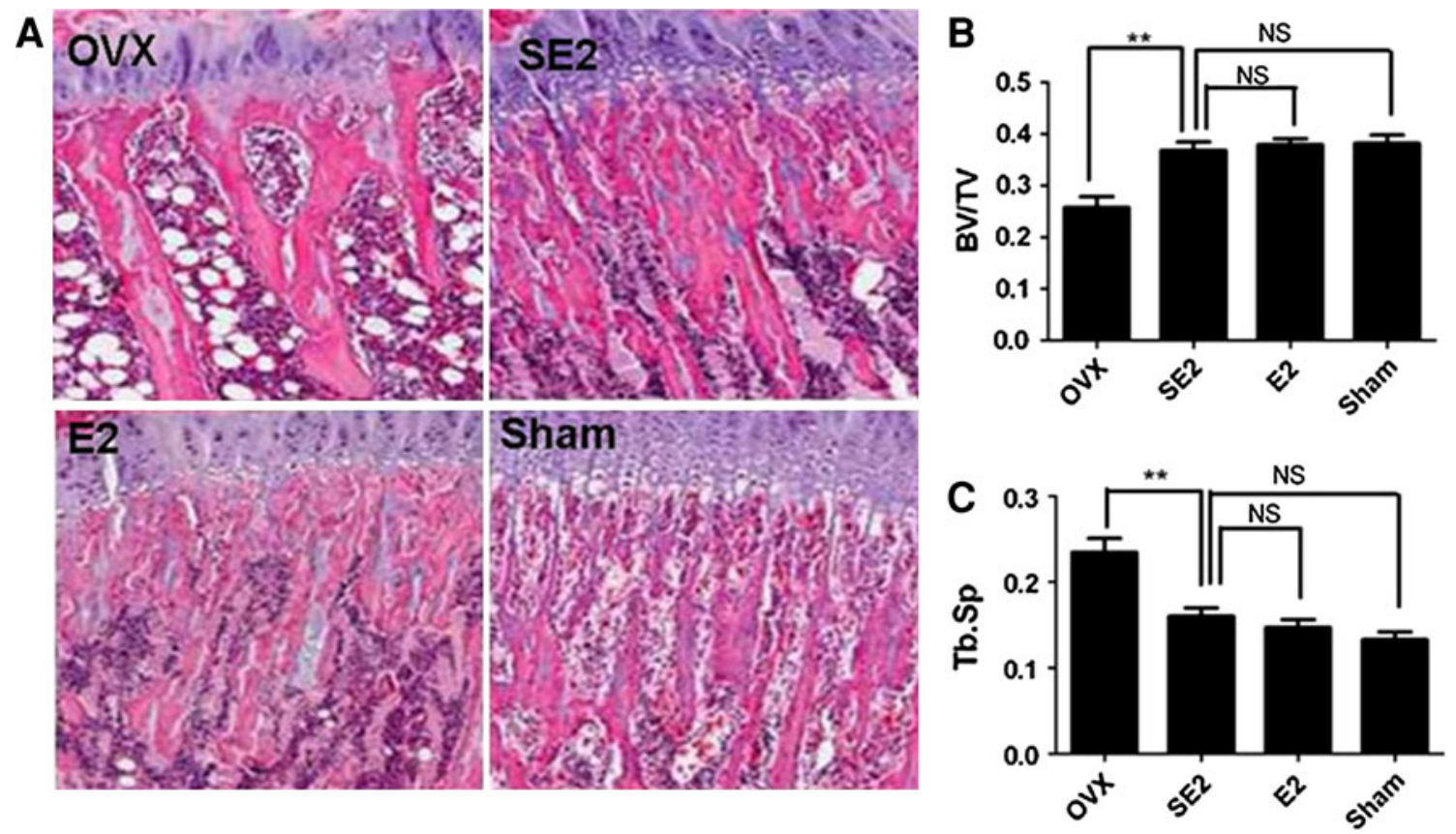

Fig. 7 Bone histology and histomorphometric analysis of the proximal tibia. $\mathrm{SE}_{2}$ treatment was effective in maintaining the normal morphology of the proximal tibia compared to the OVX group, which was similar to the $\mathrm{E}_{2^{-}}$and sham-treated group (HE, original magnification $\times 40$ ) $($ a). The ratios of bone volume to total volume

was similar to the $\mathrm{E}_{2}$ - and sham-treated groups, and was significantly increased compared with the OVX group (Fig. 8c). The results showed that BV/TV, Tb.Th and Tb.N were significantly increased, whereas $\mathrm{Tb} . \mathrm{Sp}$ was significantly decreased in the $\mathrm{SE}_{2}$ group compared with the OVX group, and these parameters in the $\mathrm{SE}_{2}$ group were similar to values in the sham-treated groups (Fig. $8 \mathrm{~d}-\mathrm{g}$ ).

Biomechanical Analyses

The femoral mechanical properties were evaluated by the three-point bending test after 12 weeks of treatment, and all femora displayed a load-displacement curve typical for a long bone. As expected, OVX led to weaker mechanical properties of femurs reflected by lower ultimate stress, ultimate load, modulus and stiffness. $\mathrm{SE}_{2}$ treatment was effective in preventing OVX-induced loss of bone, strength and it exerted an effect identical to that of either $E_{2}$ or sham operation on these same properties (Fig. 9).

\section{Discussion}

In adults, bone is continuously remodeled throughout life, with damaged bone removed and replaced with new bone, then bone composition and architecture restructured so as to maintain bone strength [30]. During bone remodeling, it
(BV/TV) and trabecular separation (Tb.Sp) in the $\mathrm{SE}_{2}$ group were significantly different from the OVX group $(* * p<0.01)$ and similar to the $\mathrm{E}_{2^{-}}$and sham-treated groups $(\mathrm{NS}, p>0.05)(\mathbf{b}, \mathbf{c})$. There were six replicate samples in each group

is of crucial importance to maintain a precise balance between osteoclastic bone resorption and osteoblastic bone formation to keep the integrity of the bone; any dissociation of the balance in bone remodeling leads to osteopetrosis or osteoporosis [31]. Loss of estrogens increases the rate of bone remodeling by removing restraining effects on osteoblastogenesis and osteoclastogenesis, and it also causes a focal imbalance between resorption and formation by prolonging the life span of osteoclasts and shortening the life span of osteoblasts [32]. The imbalance between bone resorption and formation results in the loss of bone mass and deterioration of trabecular bone microarchitecture. Although estrogens can reduce the rate of bone loss, it has many drawbacks such as cancer and cardiovascular disease. If a new type of estrogen could exert effects on bone locally, the side effects caused by estrogen would be diminished. An OVX rat model, which artificially produces estrogen deficiency, has been used for the study of postmenopausal osteoporosis and has served widely as an animal model to investigate the effects of therapeutic agents on bone mass and structure [33, 34].

Through the Mannich reaction, estradiol was integrated with a calcium chelator, IDA, which has high affinity for bone, and a bone-seeking estrogen $\left(\mathrm{SE}_{2}\right)$ was developed. First, we labeled $\mathrm{E}_{2}$ and $\mathrm{SE}_{2}$ with ${ }^{3} \mathrm{H}$ and detected the DPM of $\mathrm{E}_{2}{ }^{3} \mathrm{H}$ and $\mathrm{SE}_{2}{ }^{3} \mathrm{H}$ to reflect the distribution of $\mathrm{E}_{2}$ and $\mathrm{SE}_{2}$ in organs. The results showed that $\mathrm{SE}_{2}$ had significant 


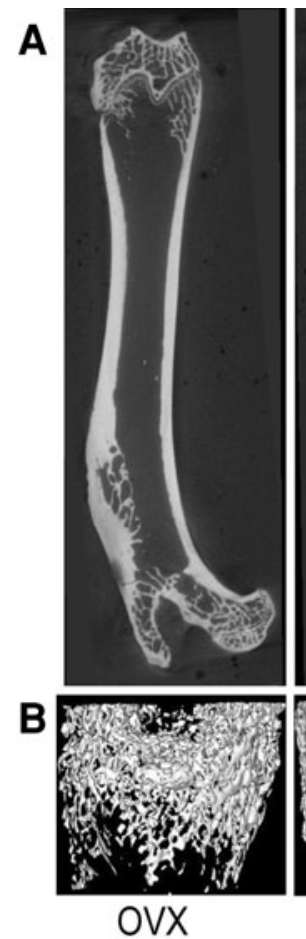

OVX

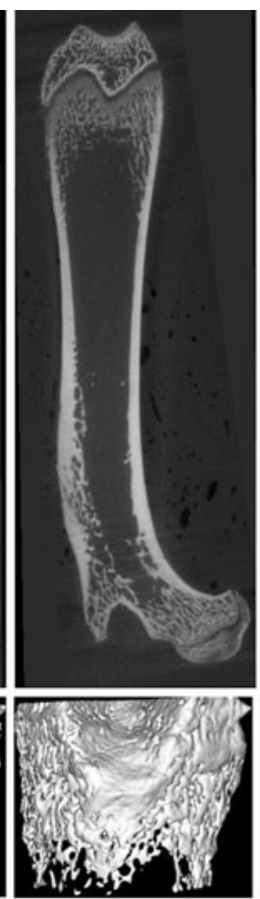

SE2
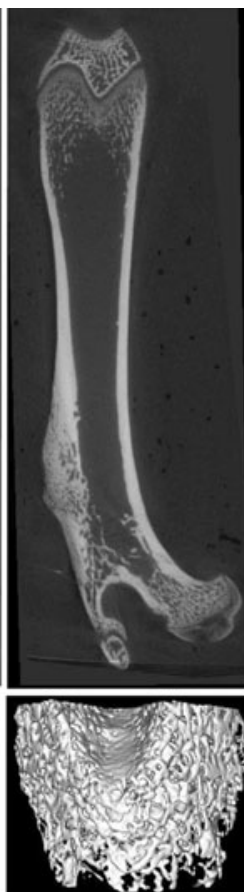

E2

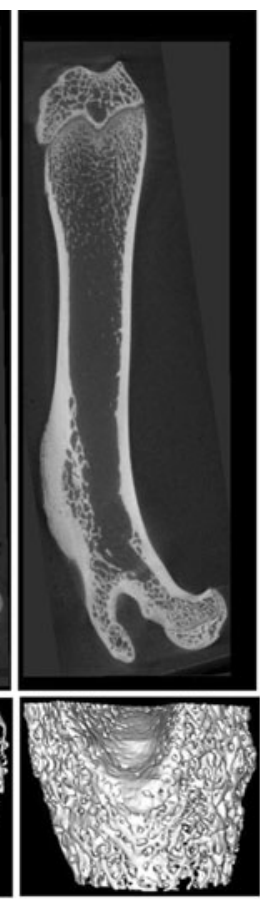

Sham
E

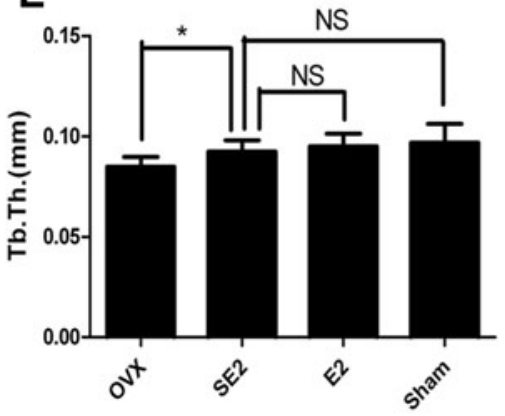

$\mathbf{F}$

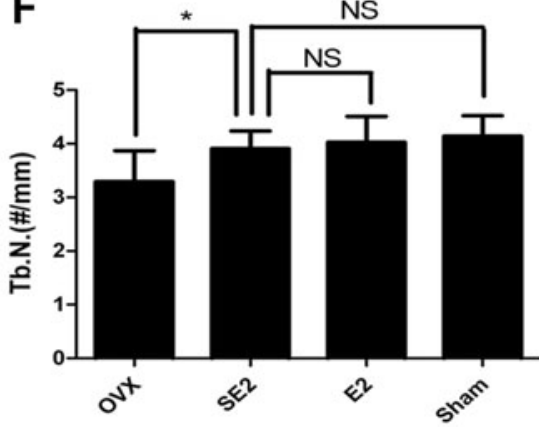

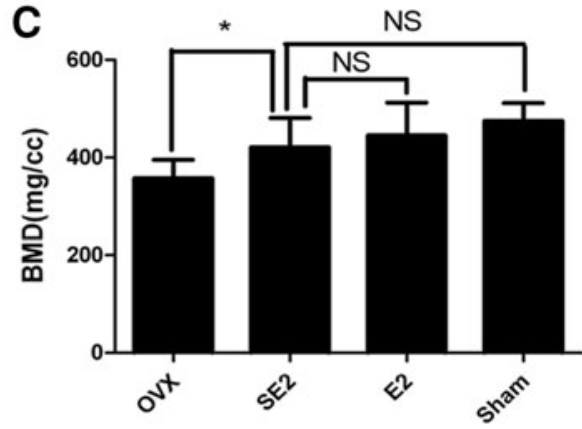
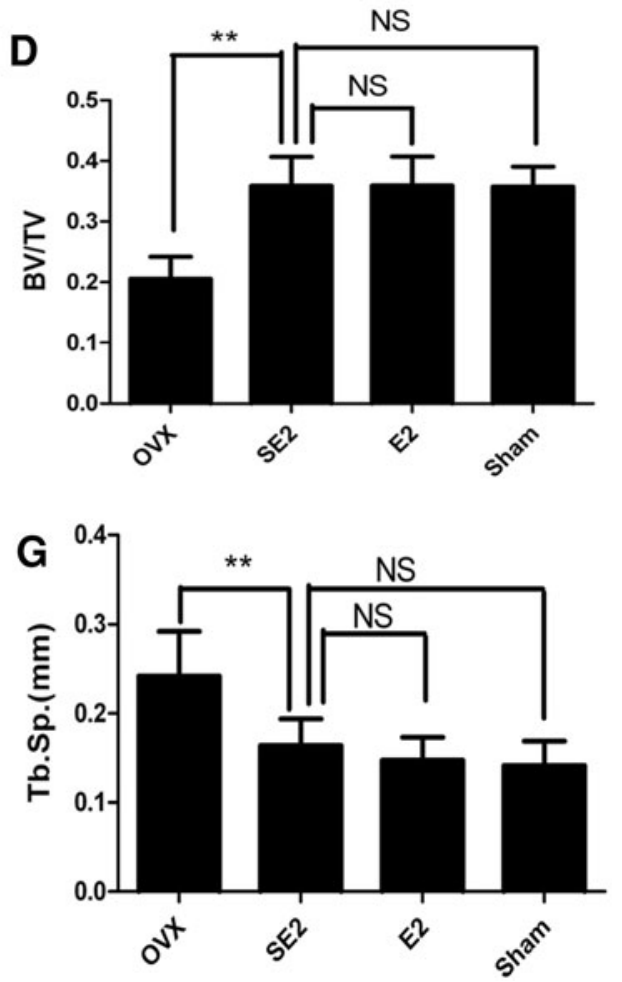

Fig. 8 Bone microarchitectural changes in the distal femur assessed by micro-CT. The images of the trabecular bone in the distal femur (a) and the reconstructed 3D images in the area of the region of interest (b) showed that $\mathrm{SE}_{2}$ and $\mathrm{E}_{2}$ treatment provided for better bone mass and trabecular architecture than the OVX group. BMD in the $\mathrm{SE}_{2}$ groups was increased compared with the OVX group $(* * p<0.01)$ and similar to that of the $\mathrm{E}_{2^{-}}$and sham-treated groups (NS, $p>0.05$ ) (c). Ratios of bone volume per total volume (BV/TV),

affinity for bone but lower affinity for ovary and uterus than did $E_{2}$. Second, $\mathrm{SE}_{2}$ maintained its high affinity for estrogen receptor alpha similar to that of $E_{2}$. Therefore, $\mathrm{SE}_{2}$ would likely retain its estrogen effect locally in bone and reduce the effects on other organs of mice at the same time.

Biochemical markers of bone turnover have been widely used as measures of the status of bone remodeling. The biochemical markers of bone turnover used in clinical and experimental studies include osteocalcin and ALP (a sensitive marker of bone formation) and CTX (a sensitive trabecular thickness (Tb.Th), and trabecular number (Tb.N) in the $\mathrm{SE}_{2}$ groups were significantly increased compared with the OVX group $\left({ }^{* *} p<0.01, * p<0.05\right)$ and similar to indices in the $\mathrm{E}_{2^{-}}$and shamtreated groups (NS, $p>0.05)(\mathbf{d}-\mathbf{f})$. Trabecular separation (Tb.Sp) was significantly decreased in the $\mathrm{SE}_{2}$ group compared with the OVX group $\left({ }^{*} p<0.01\right)$ and was similar to the $\mathrm{E}_{2^{-}}$and sham-treated groups (NS, $p>0.05)(\mathrm{g})$. There were six replicate samples in each group

marker of bone resorption) [26]. In the present study, OVX rats were found to have higher osteocalcin, ALP and CTX levels than the $\mathrm{SE}_{2}$ group, indicating decreased bone turnover due to $\mathrm{SE}_{2}$ treatment.

As measured by micro-CT, OVX resulted in a loss of BMD in the metaphyseal region of the distal femur. As expected, $\mathrm{E}_{2}$ almost completely prevented OVX-induced bone loss, and $\mathrm{SE}_{2}$ was also effective in inhibiting the loss of $\mathrm{BMD}$ in OVX rats compared with $\mathrm{E}_{2}$. BMD is one of the major determinants of bone strength, and decreased bone mass is a useful predictor of increased fracture risk. As 

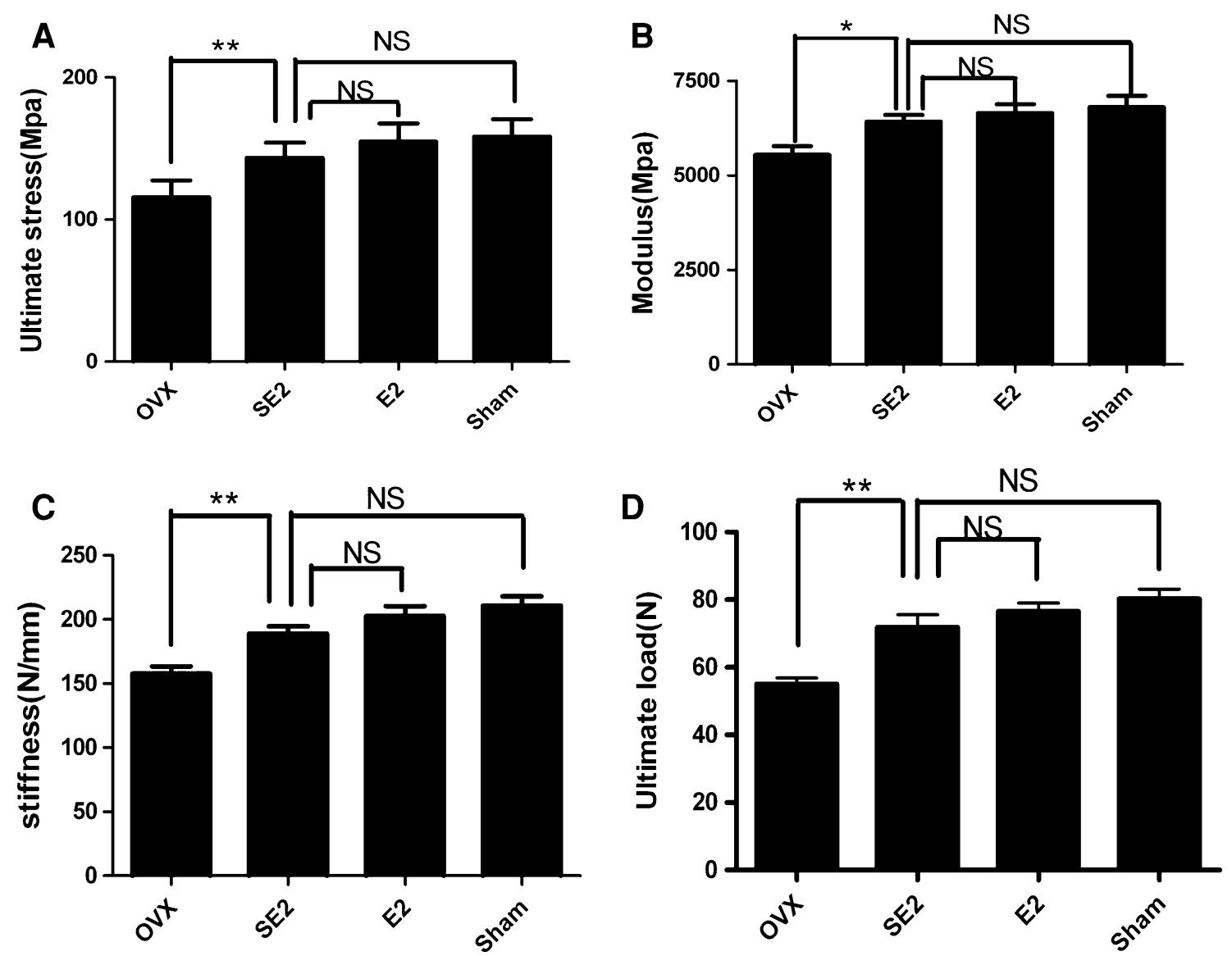

Fig. 9 Biomechanical analyses of femur after 12 weeks. $\mathrm{SE}_{2}$ treatment was effective in increasing mechanical properties of femoral ultimate stress (a), modulus (b), stiffness (c), and ultimate load (d) compared to the OVX group $(* * p<0.01, * p<0.05) ; \mathrm{SE}_{2}$

measured by micro-CT analysis, the structure of trabecular bone deteriorated in OVX rats; Tb.N, Tb.Th and BV/TV at the distal metaphysis of the femur were significantly reduced 12 weeks after $\mathrm{OVX} . \mathrm{E}_{2}$ and $\mathrm{SE}_{2}$ both effectively inhibited the deterioration of the trabecular architecture of OVX rats compared with the sham-treated groups. Tb.N, Tb.Th and $\mathrm{BV} / \mathrm{TV}$ at the distal metaphysis of the femur were significantly increased in the $\mathrm{E}_{2}$ and $\mathrm{SE}_{2}$ groups compared to the OVX groups. Bone histomorphometric analysis further verified that $\mathrm{SE}_{2}$ could prevent bone loss induced by OVX. In addition to $\mathrm{BMD}$, the biomechanical characteristics of bone also reflect bone strength. Therefore, evaluating the quality of bone by biomechanical analyses is another reliable strategy. OVX decreased the mechanical strength of femurs. Both $\mathrm{E}_{2}$ and $\mathrm{SE}_{2}$ treatment effectively maintained the mechanical strength of the femurs.

It is well known that OVX induces weight gain in rats, which is considered to protect the skeletal system by providing an increased mechanical stimulus in a state of estrogen deficiency [35]. In our study, at the end of the treatment, the rats of the $\mathrm{OVX}$ group and the $\mathrm{SE}_{2}$ group

treatment also exerted the same effects on the mechanical properties of femora, compared with the $\mathrm{E}_{2^{-}}$and sham-treated groups (NS, $p>0.05)$. There were six replicate samples in each group

exhibited a greater body weight than those of the shamtreated group, while the rats of the $\mathrm{E}_{2}$ group had a slightly lower body weight than the sham-operated rats. Interestingly, the $\mathrm{E}_{2}$ group still exhibited a greater distal femoral BMD. Given the 2-fold influences of OVX and reduced body weight, these data indicated that $\mathrm{E}_{2}$ had a marked effect on bone. However, OVX resulted in a lower BMD with a greater larger body weight. Therefore, simply increasing the body weight cannot maintain the BMD of OVX rats. This demonstrates that the increasing body weight plays a less important role in preventing bone loss in OVX rats. In contrast, although the OVX rats treated with $\mathrm{SE}_{2}$ also showed a greater body weight, the bone loss was effectively inhibited, demonstrating that $\mathrm{SE}_{2}$ played a very important role in preventing bone loss in OVX rats.

OVX resulted in a pronounced atrophy of the uterus, which could be prevented by $E_{2}$ treatment. The uterine weight and the endometrial thickness of the rats in $E_{2}$ group were not significantly different from that in the sham-treated group, which indicated that $\mathrm{E}_{2}$ could promote the hypertrophy of endometria in OVX rats. This 
hypertrophy could be one of the most important mechanisms for the estrogen-induced increase in the risk of uterine bleeding and endometrial cancer. However, endometria in the $\mathrm{OVX}$ rats treated with $\mathrm{SE}_{2}$ were atrophied, with no significant difference from the OVX group, indicating that $\mathrm{SE}_{2}$ did not promote hypertrophy of endometria. This phenomenon may demonstrate that $\mathrm{SE}_{2}$ treatment can diminish the uterine complications caused by the application of $\mathrm{E}_{2}$. The uterus has abundant estrogen receptors. However, in our experiment, uterine atrophy in OVX rats treated with $\mathrm{SE}_{2}$ demonstrated that $\mathrm{SE}_{2}$ had only a slight effect on uterine estrogen receptors. The reason is that $\mathrm{SE}_{2}$ has a greater affinity for bone than for uterus.

Generally, very low levels of estrogen mostly prevent uterine atrophy and weight gain. In this study, $\mathrm{SE}_{2}$ administration had not prevented the uterine atrophy and weight gain. The reason is that the dose of $\mathrm{SE}_{2}$ in this study is low and it has high affinity for bone and lower affinity for ovary and uterus. The dose of $\mathrm{SE}_{2}$ is inadequate to prevent uterine atrophy and weight gain in this study. Whether a larger dose of $\mathrm{SE}_{2}$ would promote endometrial hypertrophy in OVX rats requires further study.

In conclusion, we showed that $\mathrm{SE}_{2}$ was effective in preventing OVX-induced bone loss in rats. In addition, $\mathrm{SE}_{2}$ exhibited few side effects on body weight or uterine hypertrophy, which was beneficial in reducing the adverse effects caused by $\mathrm{E}_{2}$ treatment. Therefore, $\mathrm{SE}_{2}$ may be a better choice than $\mathrm{E}_{2}$ for the prevention of postmenopausal osteoporosis.

Acknowledgments This work was supported by the National Natural Science Foundation of China (Grant 30872641), Shanghai Natural Science Foundation (Grant 11ZR1434100) and Shanghai Municipal Health Bureau project (Grant 2010117).

Open Access This article is distributed under the terms of the Creative Commons Attribution License which permits any use, distribution, and reproduction in any medium, provided the original author(s) and the source are credited.

\section{References}

1. Cummings SR, Melton LJ (2002) Epidemiology and outcomes of osteoporotic fractures. Lancet 359(9319):1761-1767

2. Pacifici R (1996) Estrogen, cytokines, and pathogenesis of postmenopausal osteoporosis. J Bone Miner Res 11:1043-1051

3. Inada M, Miyaura C (2010) Cytokines in bone diseases. Cytokine and postmenopausal osteoporosis. Clin Calcium 20:1467-1472

4. Pacifici R (1998) Cytokines, estrogen, and postmenopausal osteoporosis - the second decade. Endocrinology 139:2659-2661

5. Novack DV (2007) Estrogen and bone: osteoclasts take center stage. Cell Metab 6:254-256

6. Hadjidakis DJ, Androulakis II (2006) Bone remodeling. Ann N Y Acad Sci 1092:385-396

7. Raisz LG (1993) Bone cell biology: new approaches and unanswered questions. J Bone Miner Res 8(Suppl 2):S457-S465
8. Barrett-Connor E, Mosca L, Collins P, Geiger MJ, Grady D, Kornitzer M, McNabb MA, Wenger NK (2006) Effects of raloxifene on cardiovascular events and breast cancer in postmenopausal women. N Engl J Med 355:125-137

9. Güerri-Fernández RC, Diez-Perez A (2012) Is there a future for selective estrogen-receptor modulators in osteoporosis? Ther Adv Musculoskelet Dis 4:55-59

10. Simon JA (2012) What's new in hormone replacement therapy: focus on transdermal estradiol and micronized progesterone. Climacteric 15(Suppl 1):3-10

11. Beral V, Banks E, Reeves G (1999) Use of HRT and the subsequent risk of cancer. J Epidemiol Biostat 4:191-210

12. LaCroix AZ, Burke W (1997) Breast cancer and hormone replacement therapy. Lancet 350(9084):1042-1043

13. Lacey JV Jr, Mink PJ, Lubin JH (2002) Menopausal hormone replacement therapy and risk of ovarian cancer. JAMA 288: 334-341

14. Daly E, Vessey MP, Hawkins MM (1996) Risk of venous thromboembolism in users of hormone replacement therapy. Lancet 348(9033):977-980

15. Lidegaard Ø, Løkkegaard E, Jensen A, Skovlund CW, Keiding N (2012) Thrombotic stroke and myocardial infarction with hormonal contraception. N Engl J Med 366:2257-2266

16. Mueck AO (2012) Postmenopausal hormone replacement therapy and cardiovascular disease: the value of transdermal estradiol and micronized progesterone. Climacteric 15(Suppl 1):11-17

17. Takeyama M, Nogami K, Okuda M, Sakurai Y, Matsumoto T, Tanaka I, Yoshioka A, Shima M (2008) Selective factor VIII and $\mathrm{V}$ inactivation by iminodiacetate ion exchange resin through metal ion adsorption. Br J Haematol 142:962-970

18. Wang D, Miller SC, Kopecková P, Kopecek J (2005) Bone-targeting macromolecular therapeutics. Adv Drug Deliv Rev 57: 1049-1076

19. Miller SC, Pan H, Wang D, Bowman BM, Kopecková P, Kopecek J (2008) Feasibility of using a bone-targeted, macromolecular delivery system coupled with prostaglandin $\mathrm{E}(1)$ to promote bone formation in aged, estrogen-deficient rats. Pharm Res 25:2889-2895

20. Bauss F, Esswein A, Reiff K, Sponer G, Müller-Beckmann B (1996) Effect of 17beta-estradiol-bisphosphonate conjugates, potential bone-seeking estrogen pro-drugs, on 17beta-estradiol serum kinetics and bone mass in rats. Calcif Tissue Int 59:168-173

21. Gallo D, Zannoni GF, Apollonio P, Martinelli E, Ferlini C, Passetti G, Riva A, Morazzoni P, Bombardelli E, Scambia G (2005) Characterization of the pharmacologic profile of a standardized soy extract in the ovariectomized rat model of menopause: effects on bone, uterus, and lipid profile. Menopause 12: $589-600$

22. Mo Z, Jiao X, Su H, Zheng H, Weng L (1998) The estrogenic activities of 2-[3-estrone- $N$-ethyl-piperazine-methyl]tetracycline (XW630) - a new compound with anti-osteoporosis activity. Yao Xue Xue Bao 33:645-649

23. Neale JR, Richter NB, Merten KE, Taylor KG, Singh S, Waite LC, Emery NK, Smith NB, Cai J, Pierce WM Jr (2009) Bone selective effect of an estradiol conjugate with a novel tetracycline-derived bone-targeting agent. Bioorg Med Chem Lett 19:680-683

24. Iwaniec UT, Samnegård E, Cullen DM (2001) Maintenance of cancellous bone in ovariectomized, human parathyroid hormone [hPTH(1-84)]-treated rats by estrogen, risedronate, or reduced hPTH. Bone 29:352-360

25. Mukherjee M, Das AS, Das D (2006) Effects of garlic oil on postmenopausal osteoporosis using ovariectomized rats: comparison with the effects of lovastatin and 17beta-estradiol. Phytother Res 20:21-27

26. Kim TH, Jung JW, Ha BG, Hong JM, Park EK, Kim HJ, Kim SY (2011) The effects of luteolin on osteoclast differentiation, 
function in vitro and ovariectomy-induced bone loss. J Nutr Biochem 22:8-15

27. Duvall CL, Robert Taylor W, Weiss D, Guldberg RE (2004) Quantitative microcomputed tomography analysis of collateral vessel development after ischemic injury. Am J Physiol Heart Circ Physiol 287:H302-H310

28. Yoon KH, Cho DC, Yu SH, Kim KT, Jeon Y, Sung JK (2012) The change of bone metabolism in ovariectomized rats: analyses of microCT scan and biochemical markers of bone turnover. J Korean Neurosurg Soc 51:323-327

29. Zhao Q, Shen X, Zhang W, Zhu G, Qi J, Deng L (2012) Mice with increased angiogenesis and osteogenesis due to conditional activation of HIF pathway in osteoblasts are protected from ovariectomy induced bone loss. Bone 50:763-770

30. Seeman E, Delmas PD (2006) Bone quality - the material and structural basis of bone strength and fragility. N Engl J Med 354: $2250-2261$
31. Karsdal MA, Martin TJ, Bollerslev J, Christiansen C, Henriksen K (2007) Are nonresorbing osteoclasts sources of bone anabolic activity? J Bone Miner Res 22:487-494

32. Manolagas SC (2000) Birth and death of bone cells: basic regulatory mechanisms and implications for the pathogenesis and treatment of osteoporosis. Endocr Rev 21:115-137

33. McCann RM, Colleary G, Geddis C (2008) Effect of osteoporosis on bone mineral density and fracture repair in a rat femoral fracture model. J Orthop Res 26:384-393

34. Fox J, Miller MA, Newman MK (2006) Daily treatment of aged ovariectomized rats with human parathyroid hormone (1-84) for 12 months reverses bone loss and enhances trabecular and cortical bone strength. Calcif Tissue Int 79:262-272

35. Lin JC, Grampp S, Link T (1999) Fractal analysis of proximal femur radiographs: correlation with biomechanical properties and bone mineral density. Osteoporos Int 9:516-524 